\section{Commentary: Surgery for small cell lung cancer: This is the way}

\author{
Thomas A. D’Amico, MD
}

The role of surgery for limited-stage small cell lung cancer (SCLC) continues to evolve: Numerous studies and guidelines have demonstrated the role of resection in carefully selected patients. ${ }^{1}$ For example, Yang and colleagues ${ }^{2}$ demonstrated superior survival with surgery compared with chemoradiation for patients with limited-stage SCLC with N0 disease as well as N1 disease. ${ }^{3}$ The role of adjuvant chemotherapy for patients with early-stage SCLC has also been demonstrated. ${ }^{4}$ Despite these findings, the rate of surgery in these patients does not appear to have increased. ${ }^{5}$

Analyses of outcomes of surgical treatment of SCLC are difficult to interpret because the treatment guidelines do not replicate the guidelines for non-small cell lung cancer, and the diagnosis of early-stage SCLC is often not available at the time of decision making regarding surgery, complicating preoperative decision making and multidisciplinary care. ${ }^{1,4,6}$ Furthermore, in these population-based studies, it is difficult to control for the influence of selection bias (eg, offering surgery or adjuvant therapy only for the fittest patients).

As data emerge from population-based studies, results from single or multiple-institution studies should also be considered in treatment guideline development; it is unlikely that prospective, randomized trials will be practical for the study of the surgical role in SCLC. Zhou and colleagues ${ }^{7}$ present an important multi-institutional study, including 164 patients with limitedstage SCLC. The authors analyze the outcomes of patients after surgical resection for limited-stage lung cancer, and both node-negative status and the use of adjuvant chemotherapy are identified as important predictors of survival. It is very important to have multi-institutional studies in addition to national database studies to continue to develop guidelines for SCLC, and the identification of these 2 important prognostic factors will inform guideline development in the future.

\footnotetext{
From the Division of Thoracic Surgery, Department of Surgery, Duke University Medical Center, Durham, NC.

Disclosures: The author reported no conflicts of interest.

The Journal policy requires editors and reviewers to disclose conflicts of interest and to decline handling or reviewing manuscripts for which they may have a conflict of interest. The editors and reviewers of this article have no conflicts of interest.

Received for publication Nov 17, 2020; revisions received Nov 17, 2020; accepted for publication Nov 18, 2020; available ahead of print Nov 28, 2020.

Address for reprints: Thomas A. D'Amico, MD, Division of Thoracic Surgery, Department of Surgery, Duke University Medical Center, DUMC Box 3496, Duke South, White Zone, Room 3589, Durham, NC 27710 (E-mail: thomas. damico@duke.edu).

J Thorac Cardiovasc Surg 2021;161:772-3

$0022-5223 / \$ 36.00$

Copyright (c) 2020 by The American Association for Thoracic Surgery

https://doi.org/10.1016/j.jtcvs.2020.11.090
}

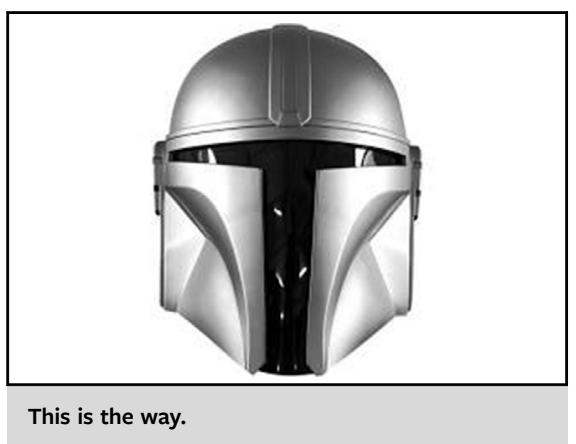

CENTRAL MESSAGE

Surgical resection within the

context of multidisciplinary care

and adhering to established

guidelines may improve the out-

comes of patients with early-

stage small cell lung cancer.

This series also identifies the difficulty in treating SCLC. More than half of patients had T1 tumors; thus, without an established diagnosis of SCLC, preresection pathologic mediastinal lymph node assessment would not be expected. However, approximately $40 \%$ of patients were found to have node-positive disease at surgery, with long-term survival of approximately $15 \%$. It is uncertain whether induction therapy would have improved survival in this group.

The National Comprehensive Cancer Network guideline algorithm for patients with clinical T1 or T2 N0 SCLC is the following: pathologic mediastinal lymph node assessment followed by surgery for patients who are not N2. ${ }^{1}$ In the present study, $15 \%$ of patients were $\mathrm{T} 3$ or $\mathrm{T} 4,19 \%$ were $\mathrm{N} 1$, and $19 \%$ were N2. Although some patients were certainly upstaged at surgery, this might not fully explain why the majority of patients beyond T2 N0 still underwent resection.

Regarding prophylactic cranial irradiation, it was only used in 43 patients, yet nearly twice that many were beyond stage I, and prophylactic cranial irradiation might have been considered in more of them. Regarding adjuvant therapy, the National Comprehensive Cancer Network guidelines recommend adjuvant chemotherapy for all patients after surgical resection, and adjuvant chemotherapy has already been demonstrated to improve survival. ${ }^{4}$ It is certain that numerous factors contributed to the fact that only $68 \%$ of patients received adjuvant chemotherapy.

This study expands our understanding of the use of surgical resection for SCLC. The power of this study, in addition to excellent results, is the highlighting of the complex issues related to management of patients with SCLC. The 
margin of improving outcomes for patients with SCLC using surgery is narrow, and outcomes are dependent on multidisciplinary decision making and treatment. Until other studies demonstrate flexibility, surgeons must strive for guideline concordance. This is the way.

\section{References}

1. NCCN Clinical Practice Guidelines in Oncology: small cell lung cancer version 1. Available at: https://www.nccn.org/professionals/physician_gls/pdf/sclc.pdf. Accessed November 17, 2020.

2. Yang C-F, Chan DY, Shah S, Yerokun B, Wang XF, D'Amico TA, et al. Long-term survival after surgery compared with concurrent chemoradiation for node-negative small cell lung cancer. Ann Surg. 2018;268:1105-12.
3. Yang C-F, Chan DY, Speicher PJ, Gulack BC, Tong BC, Hartwig MG, et al Surgery vs optimal medical management for N1 small cell lung cancer. Ann Thorac Surg. 2017;103:1767-72.

4. Yang C-F, Chan DY, Speicher PJ, Gulack BC, Wang X, Hartwig MG, et al. The role of adjuvant therapy in a population-based cohort of patients with early stage small cell lung cancer. J Clin Oncol. 2016;34:1057-64.

5. Pietanza MC. Using a population-based analysis to determine the management and treatment of early-stage small-cell lung cancer. J Clin Oncol. 2016;34:1027-9.

6. Raman V, Jawitz O, Yang CF, Voigt S, D'Amico TA, Harpole DH, et al. The effect of extent of resection on outcomes in patients with limited stage small cell lung cancer. J Thorac Cardiovasc Surg. March 22, 2020 [Epub ahead of print].

7. Zhou N, Bott M, Park BJ, Vallières E, Wilshire CL, Yasufuku K, et al. Predictors of survival following surgical resection of limited stage small cell lung cancer. J Thorac Cardiovasc Surg. 2021;161:760-71.e2.

\section{Commentary: Survival after small cell lung cancer resection: Small opportunity?}

\author{
Mark Onaitis, MD
}

Opportunities to enhance survival of patients with nonsmall cell lung cancer are common for thoracic surgeons, and algorithms for adjuvant therapy are clear. Multiple studies have demonstrated long-term survival improvement with adjuvant chemotherapy for node-positive patients. However, less is known regarding the much less common circumstance of complete resection of limited-stage small cell lung cancer. A National Cancer Database study recently demonstrated that adjuvant chemotherapy improves survival in resected small cell lung cancer patients. ${ }^{1}$ The current study helps shed some light on the topic because it demonstrates, in an analysis of patients resected at several major centers over 33 years, that adjuvant chemotherapy

\footnotetext{
From the Division of Cardiothoracic Surgery, University of California, San Diego, La Jolla, Calif.

Disclosures: The author reported no conflicts of interest.

The Journal policy requires editors and reviewers to disclose conflicts of interest and to decline handling or reviewing manuscripts for which they may have a conflict of interest. The editors and reviewers of this article have no conflicts of interest.

Received for publication Nov 15, 2020; revisions received Nov 15, 2020; accepted for publication Nov 17, 2020; available ahead of print Nov 24, 2020.

Address for reprints: Mark Onaitis, MD, Division of Cardiothoracic Surgery, University of California, San Diego, 9300 Campus Point Dr, Mailcode 7892, La Jolla, CA 92037 (E-mail: monaitis@ucsd.edu).

J Thorac Cardiovasc Surg 2021;161:773-4 $0022-5223 / \$ 36.00$

Copyright (c) 2021 Published by Elsevier Inc. on behalf of The American Association for Thoracic Surgery

https://doi.org/10.1016/j.jtcvs.2020.11.069
}

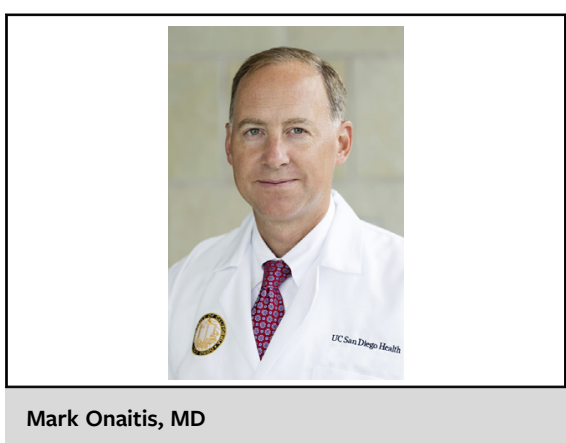

CENTRAL MESSAGE

A strategy of resection of limitedstage small cell carcinoma with anatomic resection followed by adjuvant chemotherapy may improve survival over resection followed by no chemotherapy.

improves survival after surgical resection regardless of pathologic lymph node status. ${ }^{2}$

Strengths of the article include its multi-institutional nature, the relatively large sample size for a rare clinical situation, and the long time period covered. The premise also makes sense: Small cell lung cancer usually manifests with multiple distant metastases and these patients often have excellent initial responses to systemic chemotherapy and immunotherapy. ${ }^{3}$ It thus follows that systemic chemotherapy would help patients with limited-stage disease and presumed micrometastases. However, we must take pause in interpretation of the current study. First, confounding is a large issue in a retrospective study like this. Perhaps the patients who received chemotherapy were healthier than the cohort that did not receive 